\title{
Dissociation of Inflammatory and Epithelial Responses in a Murine Model of Chronic Asthma
}

\author{
Paul S. Foster, Yang Ming, Klaus I. Matthei, lan G. Young, Jason Temelkovski, and \\ Rakesh K. Kumar
}

Division of Biochemistry and Molecular Biology (PSF, YM, KIM, IGY), John Curtin School of Medical Research, Australian National University, Canberra, Australia; and School of Pathology (JT, RKK), University of New South Wales, Sydney, Australia

\begin{abstract}
SUMMARY: To study pathogenetic mechanisms in chronic asthma, we employed a novel experimental model that replicates characteristic features of the human disease. Chronic inflammation and epithelial changes, specifically localized to the airways, were induced by repeated exposure of systemically sensitized BALB/c mice to low mass concentrations of aerosolized ovalbumin for 6 weeks. The contribution of Th2 cytokine-driven inflammation to the development of airway lesions and hyperreactivity was assessed in cytokine-deficient mice. In interleukin-5-deficient animals, intraepithelial eosinophils and chronic inflammatory cells in the lamina propria of the airways were markedly decreased; however, these animals developed epithelial hypertrophy and subepithelial fibrosis comparable with that observed in sensitized wild type mice. Airway hyperreactivity to inhaled methacholine did not develop in interleukin-5-deficient mice. In contrast, interleukin-4-deficient mice exhibited no decrease in airway inflammation, but had significantly greater epithelial hypertrophy and subepithelial fibrosis, as well as exaggerated hyperreactivity to methacholine. We conclude that interleukin-5, but not interleukin-4, plays a central role in the development of chronic inflammation of the airways and the induction of airway hyperreactivity. Furthermore, chronic epithelial and fibrotic changes occur independently of interleukin- 5 and are not required for the development of airway hyperreactivity. The dissociation between airway wall remodeling and airway hyperreactivity has important implications for therapeutic approaches to chronic asthma. (Lab Invest 2000, 80:655-662).
\end{abstract}

$A$ sthma is a major cause of chronic illness, affecting as many as $25 \%$ of schoolchildren in regions of high prevalence (Robertson et al, 1998). Clinically, the disease is characterized by airway hyperreactivity $(\mathrm{AHR})$ and symptoms of airflow obstruction. Pathologic changes include acute and chronic inflammation of the airway mucosa, with recruitment of eosinophils, which are characteristically present within the epithelial layer, as well as accumulation of $\mathrm{CD}^{+}$ T-lymphocytes in the lamina propria (Bousquet et al, 1990; Corrigan and Kay, 1996). In addition, various other lesions of the airway wall are regularly observed in human asthma, including epithelial shedding, hypertrophy, and mucous cell hyperplasia/metaplasia (Hegele and Hogg, 1996), together with fibrosis, which is predominantly in the subepithelial region but extends throughout the lamina propria (Hegele and Hogg, 1996; Wilson and Li, 1997).

The pathogenesis of these changes is far from clear. The inflammatory response appears to have an atopic/ allergic basis in at least two-thirds of asthmatic patients (McFadden and Gilbert, 1992) and the pattern of cytokine production by T-lymphocytes is consistent

Received September 28, 1999.

Address reprint requests to: Dr. P. S. Foster, Division of Biochemistry and Molecular Biology, John Curtin School of Medical Research, Australian National University, Canberra, Australia 0200. Fax: 6126249 0415; E-mail:Paul.Foster@anu.edu.au with a Th2 phenotype (secretion of interleukins 4, 5, 10, and 13) (Corrigan and Kay, 1996; Humbert et al, 1997). In particular, IL-4 and IL-5 have been implicated as key regulators of airway inflammation and hyperreactivity in clinical investigations. However, the specific roles of these cytokines remain contentious, and many fundamental questions are difficult, if not impossible, to answer in human studies. Experiments in animals suggest that the early asthmatic response is dependent on antigen-specific IgE (Lambert et al, 1998). Some investigators have suggested that AHR may be dependent on IL-4, which plays a major role in the induction of an IgE response, or on IgE itself (Brusselle et al, 1995; Corry et al, 1996; Hamelmann et al, 1997b). Several reports also indicate that IL-5, which regulates accumulation of eosinophils, plays an important role in $\mathrm{AHR}$ and the pathophysiology of changes in the respiratory epithelium (Foster et al, 1996; Hogan et al, 1997a; 1997b; 1998a; Kung et al, 1995; Nakajima et al, 1992).

Notably, all of the above studies employed models of acute allergic inflammation of the airways that center on short-term exposure of sensitized mice to relatively high concentrations of inhaled allergen, which results in recruitment of leukocytes not only to the airways but also the peripheral lung parenchyma. Acute inhalational models also lack characteristic features of chronic human asthma, including intraepithelial recruitment of eosinophils, chronic inflammatory changes, and airway wall remodeling, making it diffi- 
cult to determine the role of Th2 cytokines in the pathogenesis of these lesions. Furthermore, the allergic alveolitis may mask the specific contribution of airway wall inflammation to AHR. We have recently described a model of chronic asthma in mice (Temelkovski et al, 1998) that involves systemic sensitization of BALB/c mice and subsequent long-term inhalational challenge with low mass concentrations of antigen, which results in the development of lesions that are hallmarks of chronic human asthma. These include the accumulation of numerous intraepithelial eosinophils, together with chronic inflammation in the lamina propria, epithelial hypertrophy, mucous cell hyperplasia, and subepithelial fibrosis. Importantly, and in sharp contrast to virtually all previously reported murine experimental models of asthma, there is no evidence of alveolitis associated with the airway lesions. The mice also exhibit marked hyperreactivity to cholinergic stimuli, which can be attributed to disease of the airways rather than to parenchymal lesions.

We have employed our chronic exposure model of asthma, in combination with Th2 cytokine-deficient mice bred on to the same genetic background, to identify the contribution of inflammatory processes regulated by IL-4 and IL-5 to the induction of these characteristic pathophysiologic features. Our results indicate that IL-5 not only plays a key role in the recruitment of eosinophils to the epithelial layer but also in the induction of chronic inflammation of the airways. Furthermore, chronic inflammation directly correlates with the development of AHR. The characteristic changes of chronic asthma were not attenuated in IL-4-deficient mice. Importantly, we observed dissociation between inflammation and the development of chronic epithelial and fibrotic changes of the airways. These observations suggest that eosinophils are not required for airway wall remodeling. Moreover, they have important implications for therapeutic strategies targeting these two cytokines for the control of inflammation, remodeling, and $\mathrm{AHR}$ associated with chronic asthma.

\section{Results}

\section{Chronic Inflammation of the Airways}

As previously described (Temelkovski et al, 1998), sensitized wild type BALB/c mice developed widespread multifocal accumulation of lymphocytes, macrophages, and plasma cells in the lamina propria of the trachea after chronic inhalation exposure to aerosolized ovalbumin (Fig. 1A). This increase in the mean profile density of cells in the airway wall was statistically significant $(p<0.001$ compared with nonimmunized nonexposed control animals) whereas no significant increase was observed in nonimmunized control animals exposed to aerosolized ovalbumin (Fig. 2). Small numbers of chronic inflammatory cells, mainly plasma cells, were evident in the airways of sensitized IL-5-deficient mice exposed to aerosolized ovalbumin (Fig. 1B). This inflammatory response did not achieve statistical significance (Fig. 2). In contrast, the numbers of inflammatory cells in the lamina propria of the airways of IL-4-deficient mice tended to be greater than in sensitized wild type mice (Fig. 1C), although the difference between these two groups was not statistically significant. The reduction in inflammatory cell recruitment in IL-5-deficient mice was significant compared with both wild type mice and IL-4-deficient mice $(p<0.001)$ (Fig. 2).
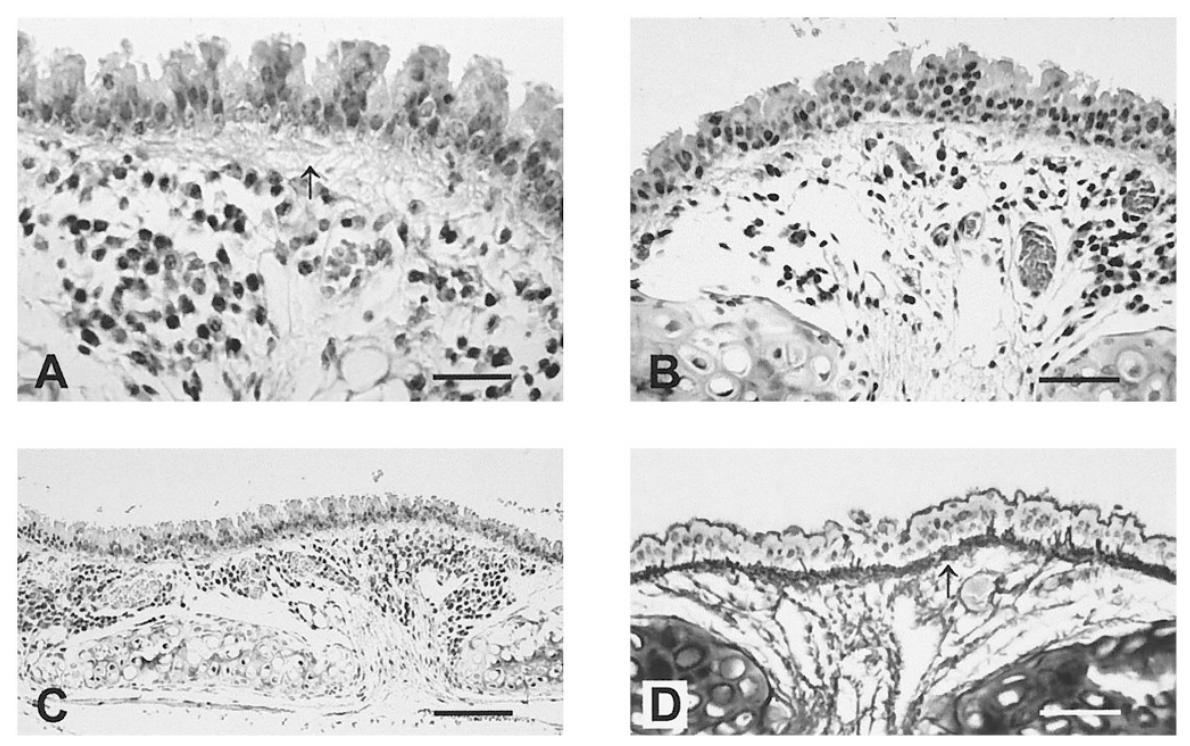

\section{Figure 1.}

Histopathologic changes in sensitized wild type and cytokine-deficient mice. A, Accumulation of numerous chronic inflammatory cells in the lamina propria of the trachea in a wild type animal. Note the epithelial thickening and the subepithelial zone of fibrillar collagenous matrix (arrow). Hematoxylin and eosin, bar $=50 \mu \mathrm{m}$. $\mathrm{B}$, Sparse inflammatory infiltrate in the lamina propria in an IL-5-deficient mouse. Hematoxylin and eosin, bar $=80 \mu \mathrm{m}$. C, Prominent aggregates of inflammatory cells throughout the lamina propria in an IL-4-deficient animal. Hematoxylin and eosin, bar $=200 \mu \mathrm{m}$. D, Marked thickening of the subepithelial collagenous zone (arrow) in an IL-5-deficient mouse. Reticulin stain, bar $=80 \mu \mathrm{m}$. 


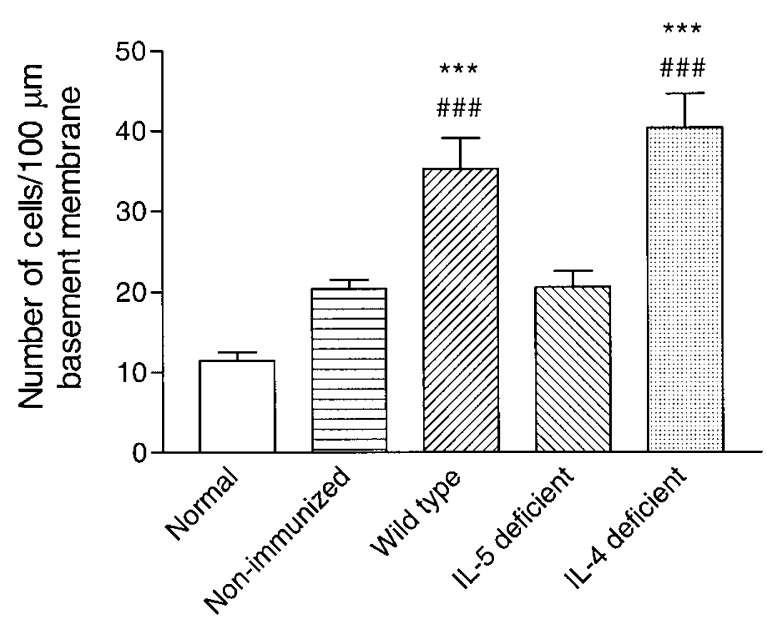

Figure 2.

Inflammation in the airway wall assessed by quantifying the number of cells in the lamina propria of the trachea. Nonimmunized $=B A L B / c$ mice, not systemically sensitized, chronically exposed to inhaled antigen. Wild type = BALB/C mice, systemically sensitized and chronically exposed. Significant differences compared with normal animals are shown as ${ }^{* *} p<0.001$. Significant differences compared with IL-5-deficient animals are shown as \#\#\# $p<0.001$.

\section{Intraepithelial Recruitment of Eosinophils}

We have previously demonstrated, in sensitized exposed wild type mice, that the recruitment of eosinophils into the epithelial layer parallels chronic inflammation of the lamina propria. This finding was confirmed in the present study, with evidence of significant numbers of intraepithelial eosinophils in these mice ( $p<0.001$ compared with nonimmunized nonexposed control animals) (Fig. 3). No significant increase was observed in nonimmunized control mice exposed to aerosolized ovalbumin. Accumulation of eosinophils was virtually abolished in sensitized exposed IL-5-deficient mice, but numbers in IL-4deficient mice were modestly increased compared with sensitized wild type mice (Fig. 3). Again, the

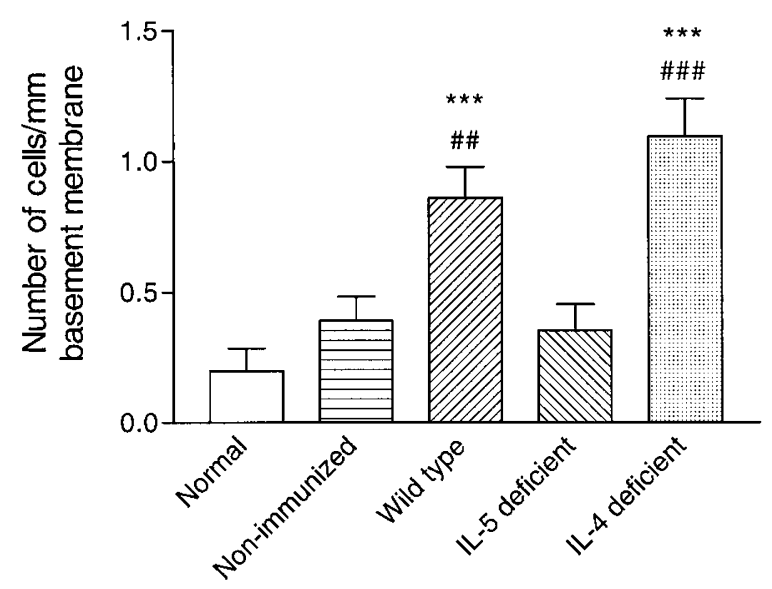

\section{Figure 3.}

Intraepithelial recruitment of eosinophils. Significant differences compared with normal animals are shown as ${ }^{\star * *} p<0.001$. Significant differences compared with IL-5-deficient animals are shown as \#\# $p<0.01$, \#\#\# $p<$ 0.001 . reduction in inflammatory cell recruitment in IL-5deficient mice was significant compared with both wild type mice $(p<0.01)$ and IL-4-deficient mice $(p<$ 0.001).

\section{Epithelial Hypertrophy}

The mean thickness of the airway epithelium was significantly increased in sensitized wild type BALB/c mice after 6 weeks of inhalation exposure to antigen ( $p<0.01$ compared with nonimmunized nonexposed control animals) (Fig. 4). No such increase was observed in nonimmunized control animals exposed to aerosolized ovalbumin. Significant hypertrophy of the epithelial cells was also observed in sensitized exposed IL-5-deficient mice $(p<0.001)$. In comparison, IL-4-deficient mice exhibited thickening of the epithelial layer, which was greater than that observed in both wild type mice $(p<0.01)$ and IL-5-deficient mice $(p<$ 0.05) (Fig. 4).

\section{Subepithelial Fibrosis}

The mean thickness of the reticulin-stained subepithelial collagenous zone was significantly increased in sensitized wild type mice exposed to antigen ( $p<$ 0.001 compared with nonimmunized nonexposed control animals) but not in nonimmunized exposed controls (Fig. 5). Subepithelial accumulation of collagen in sensitized IL-5-deficient mice exposed to aerosolized ovalbumin was comparable with that in wild type mice (Fig. 1D). Again, IL-4-deficient mice exhibited more marked changes, with significantly increased thickening of the reticulin-stained zone compared with both wild type mice and IL-5-deficient mice $(p<0.01)$ (Fig. 5).

\section{Airway Responsiveness}

In normal control animals, exposure to increasing concentrations of aerosolized methacholine increased

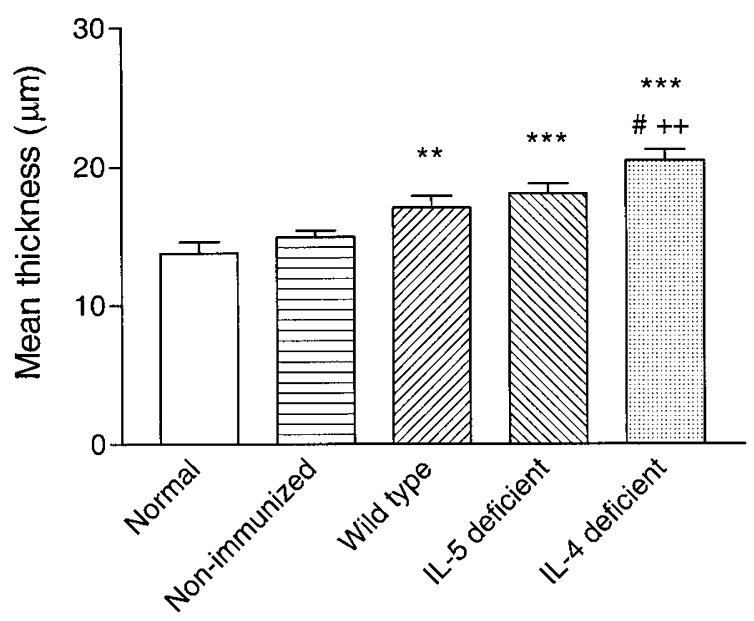

Figure 4.

Hypertrophy of the tracheal epithelium. Significant differences compared with normal animals are shown as ${ }^{* *} p<0.01,{ }^{* * *} p<0.001$. Significant difference between IL-4-deficient animals and IL-5-deficient animals is shown as \# $p<0.05$ and between IL-4-deficient animals and wild type animals as $++p<0.01$. 


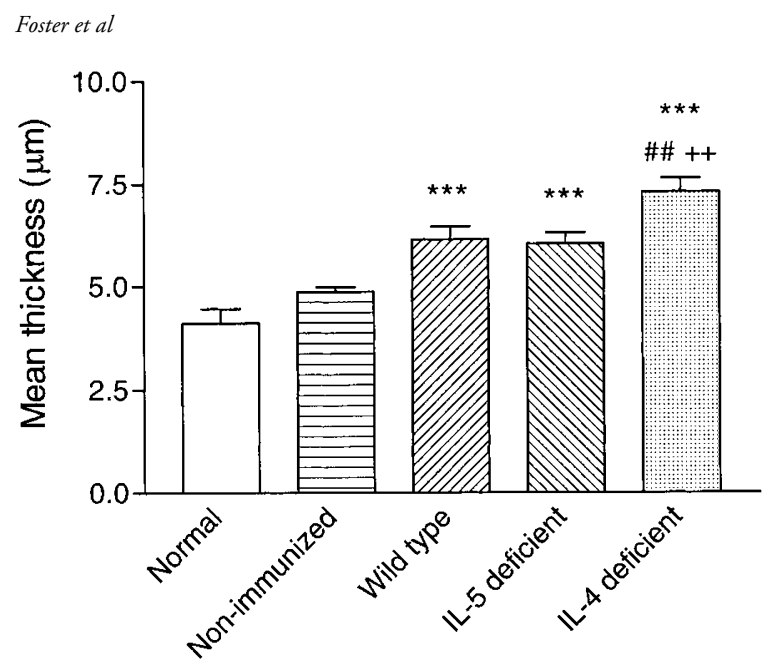

Figure $\mathbf{5}$.

Subepithelial fibrosis. Significant differences compared with normal animals are shown as *** $p<0.001$. Significant difference between IL-4-deficient animals and IL-5-deficient animals is shown as \#\# $p<0.01$ and between IL-4-deficient animals and wild type animals as $++p<0.01$.

Penh values. Relative to baseline, the increase was approximately 4-fold at a concentration of $12.5 \mathrm{mg} / \mathrm{ml}$ and reached a maximum of 6 -fold at $50 \mathrm{mg} / \mathrm{ml}$. The dose-response of nonimmunized mice exposed to ovalbumin was virtually identical, whereas that of sensitized exposed wild type animals was characteristic of airway hyperreactivity, with a left-shifted curve and increased maximal reactivity (Fig. 6). Compared with normal controls, the increase in Penh was significantly greater at methacholine concentrations of 12.5 , 25 , and $50 \mathrm{mg} / \mathrm{ml}$. In contrast, the dose-response of sensitized IL-5-deficient mice exposed to aerosolized ovalbumin closely resembled that of normal animals and of nonimmunized controls exposed to aerosolized ovalbumin. In IL-4-deficient animals, baseline Penh was significantly increased compared with both normal and wild type mice $(p<0.001)$. The increase in Penh in response to aerosolized methacholine was

significantly greater than in control animals at all concentrations tested (Fig. 6). Furthermore, this increase was significantly greater than in sensitized wild type mice, especially at low concentrations $(p<0.001$ at 3.125 and $6.25 \mathrm{mg} / \mathrm{ml}$ ).

\section{Discussion}

In this investigation, using a novel model of chronic asthma, we have shown that IL-4 and IL-5 have distinctly different roles in the pathogenesis of eosinophil recruitment, chronic inflammation, remodeling, and hyperreactivity of the airways. Importantly, our results emphasize that IL-5 is not only a key regulator of eosinophil recruitment to the airways, but also of the pathogenesis of chronic inflammation that may predispose to AHR. Wild type mice, systemically sensitized and chronically exposed to aerosolized ovalbumin, developed increased sensitivity and increased maximal reactivity to $\beta$-methacholine that correlated with infiltration of inflammatory cells. In contrast, IL-5 $(-/-)$ mice exhibited a dose-response that was virtually indistinguishable from that of normal animals. This result is in accord with our earlier findings in a shortterm exposure model (Foster et al, 1996) and consistent with studies in human asthmatics that suggest an important role for IL-5 in bronchial hyperreactivity (Humbert et al, 1997; Tang et al, 1996; Yung et al, 1995). An interesting difference from our findings in a short-term exposure model in BALB/c mice (Hogan et al, 1998b) is that mechanisms independent of IL-5 do not appear to modulate AHR in the chronic inhalational exposure model, which employs lower concentrations of inhaled antigen. Significantly, we show that IL-5 plays a major part in the development of inflammatory changes in the airway wall in chronic asthma. Because IL-5 is well-recognized to be involved in the differentiation, recruitment, and survival of eosinophils (Hogan and Foster, 1997), the diminution in the number of intraepithelial eosinophils in IL-5 (-/-) mice

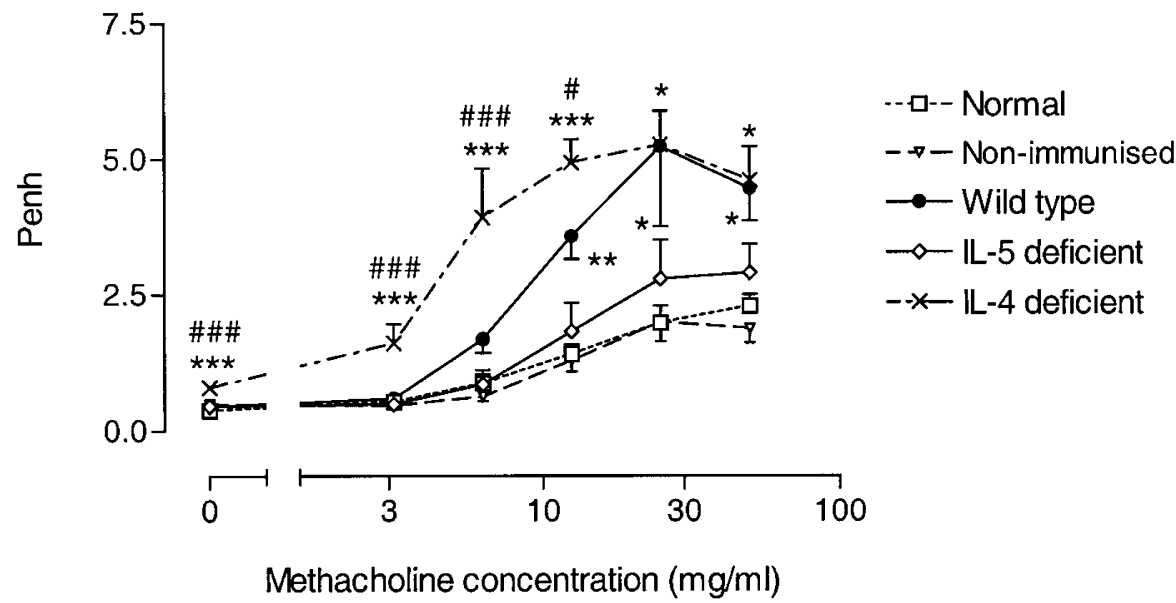

Figure 6 .

Airway reactivity assessed by change in Penh in response to increasing concentrations of aerosolized $\beta$-methacholine. Significant differences compared with normal animals are shown as ${ }^{*} p<0.05,{ }^{* *} p<0.01,{ }^{* * *} p<0.001$. Significant differences between IL-4-deficient and wild type animals are shown as \# $p<0.05$, \#\#\# $p<0.001$. 
was predictable. However, the marked decrease in the numbers of chronic inflammatory cells recruited into the lamina propria was striking and unexpected.

The mechanism associated with the inflammatory process that predisposes to the induction of AHR is unclear. Epithelial injury by mediators released by degranulating eosinophils has been implicated in the development of AHR (Coyle et al, 1994). However, the association between eosinophil recruitment and AHR demonstrated in the present study does not prove a cause-and-effect relationship. Moreover, intraepithelial eosinophils and mononuclear cells in the lamina propria were both decreased in parallel in the IL-5deficient mice, making it impossible to attribute absence of AHR to one or the other component of the inflammatory response. Recently, factors produced by CD4+ T-lymphocytes have been shown to directly modulate baseline airway reactivity and AHR (De Sanctis et al, 1997; Grunig et al, 1998; Wills-Karp et al, 1998). It remains to be determined whether factors derived from the eosinophil or other inflammatory cells are the principal mediators of AHR.

In contrast to the inflammatory changes, development of subepithelial fibrosis and of epithelial hypertrophy did not appear to be dependent on IL-5, because comparable remodeling was observed in IL-5 $(-/-)$ animals. The relationship of remodeling to AHR and/or fixed airflow obstruction in human asthmatics remains controversial (Bento and Hershenson, 1998). Importantly, our studies clearly indicate that airway wall remodeling is not of itself responsible for the induction of AHR. Furthermore, we have also established that development of subepithelial fibrosis and epithelial hypertrophy is not correlated with airway wall inflammation or the presence of intraepithelial eosinophils. These findings suggest that inflammatory cell-derived growth factors might be less important in the pathogenesis of airway wall remodeling than, for example, mediators produced by airway epithelial cells in response to injury (Zhang et al, 1999). In this context, it is noteworthy that human asthmatic airway epithelium exhibits enhanced immunoreactivity for epidermal growth factor (Amishima et al, 1998) and transforming growth factor- $\beta$ (Vignola et al, 1997). Examination of the expression of these and other growth factors by airway epithelium in our model of chronic asthma would therefore be of considerable interest.

Although IL-4 plays a key role in the development of Th2 type cells and in the production of $\lg \mathrm{E}$, it was noteworthy that both accumulation of chronic inflammatory cells in the lamina propria of the airways and intraepithelial recruitment of eosinophils in IL-4 (-/-) mice were at least equivalent to the responses in wild type animals. However, epithelial hypertrophy and subepithelial fibrosis were both significantly increased in the absence of $\mathrm{IL}-4$, relative to the changes observed in wild type animals. The increased airway wall remodeling may have predisposed to the increased baseline values of Penh in these mice, as Penh reflects the pattern of spontaneous respiration. IL-4 (-/-) mice were also hyperreactive to inhaled $\beta$-methacholine at all concentrations tested and exhibited significantly greater reactivity to this agonist at lower concentrations than did wild type mice. The results in IL-4-deficient mice support and extend our previous observations in a short-term exposure model (Foster et al, 1996), which showed that inflammation and AHR in these mice were equivalent to wild type animals. Furthermore, using this experimental model of chronic asthma, we have shown that IL-4 plays a hitherto unrecognized role in regulating airway remodeling. We have previously demonstrated that the IL-4deficient mice do not produce lgE after intraperitoneal sensitization with ovalbumin (Hogan et al, 1998b). Thus, the results reported herein suggest that chronic inflammation and remodeling of the airway wall are not dependent on an IgE response.

The mechanism whereby IL-4 partially suppresses processes of airway remodeling may relate to the anti-inflammatory action of this cytokine and its ability to down-regulate production of pro-inflammatory mediators such as tumor necrosis factor- $\alpha$ (TNF- $\alpha$ ) (Brunet et al, 1997; Donnelly et al, 1990; Hart et al, 1989). It is possible that the absence of this regulatory mechanism in IL-4 (-/-) mice may account for the prominent inflammation, epithelial hypertrophy, and fibrosis in these animals. TNF- $\alpha$ is also a significant mediator of AHR, both in humans and animal experimental models (Thomas et al, 1995; Yu et al, 1997). Thus, unregulated production of this cytokine, for example by macrophages, mast cells, or airway epithelial cells (Shah et al, 1995), could explain the increased sensitivity of animals to low concentrations of $\beta$-methacholine.

In conclusion, our data provide new insights into the processes that may regulate the pathophysiologic features of chronic asthma. In particular, we have demonstrated that IL-4 and IL-5 have important but strikingly dissimilar roles in the pathogenesis of the lesions of chronic asthma. Both the recruitment of eosinophils into the airway epithelium and the accumulation of chronic inflammatory cells in the airway wall are dependent on IL-5. Furthermore, this cytokine is crucial to the development of hyperreactivity of the airways. In contrast, IL-4 may in part down-regulate airway inflammation, airway wall remodeling, and hyperreactivity to cholinergic stimulation. Importantly, comparison of data from these two cytokine-deficient mouse strains indicates that airway wall remodeling is not simply a consequence of inflammation, nor does it directly correlate with AHR. These findings are highly pertinent to the development of therapeutic strategies for chronic asthma that target specific cytokines.

\section{Materials and Methods}

\section{Animals}

Specific pathogen-free female BALB/c mice aged 8-10 weeks were obtained from CULAS, Sydney, Australia. IL-5 (-/-) (Kopf et al, 1996) and IL-4 (-/-) mice (Noben-Trauth et al, 1996) on a BALB/c background were obtained from pathogen-free facilities at the Australian National University. Animals were main- 
tained in a laminar flow holding unit (Gelman Sciences, Sydney, Australia) and housed in autoclaved cages on autoclaved bedding in an air-conditioned room on a 12 hour light/dark cycle. Autoclaved food and acidified water were provided ad libitum throughout. All experimental procedures complied with the requirements of the Animal Care and Ethics Committee of the University of New South Wales (ref. nos. 95/18 and 98/29).

\section{Sensitization and Inhalational Exposure}

This was performed as previously described (Temelkovski et al, 1998). Mice were sensitized by an intraperitoneal injection of $10 \mu \mathrm{g}$ of alum-precipitated chicken egg ovalbumin (Grade V, $\geq 98 \%$ pure, Sigma, St. Louis, Missouri; unless otherwise specified, all chemicals were obtained from this source) 21 days and 7 days (booster injection) before inhalational exposure. Experimental groups comprising 10-12 immunized and boosted animals were exposed to aerosolized ovalbumin for 30 minutes/day on 3 days/week for 6 weeks in a whole-body inhalation exposure system (Unifab Corporation, Kalamazoo, Michigan). During the exposure, the animals were held in wire flow-through cage racks, and filtered air was drawn through the $0.5 \mathrm{~m}^{3}$ inhalation chamber at a flow rate of $250 \mathrm{~L} /$ minute. A solution of $2.5 \%$ ovalbumin in normal saline was aerosolized by delivery of compressed air to a sidestream jet nebulizer (Trimed, Sydney, Australia) and injected into the airstream entering the chamber. The concentration and size distribution of particles within the breathing zone of the mice were continuously and cumulatively monitored using a light scatter device (PCAM-TX, PPM, Knoxville, Tennessee). Particle concentration was maintained in the range of $10-20 \mathrm{mg} / \mathrm{m}^{3}$ by controlling the airflow into the nebulizer. Control groups were nonimmunized animals exposed as above, as well as nonimmunized nonexposed normal animals.

\section{Blood and Tissue Collection}

At the beginning and the end of the exposure period, mice were bled by retro-orbital puncture using heparinized capillary tubes. Plasma was diluted 1:20 in phosphate-buffered saline, and titers of ovalbuminspecific IgG antibodies were subsequently determined using an assay similar to that previously described (Hogan et al, 1997b) to confirm that systemic sensitization was successful.

Tissues for histopathologic examination were collected 48 hours after the last inhalational exposure and fixed in $10 \%$ buffered formalin overnight. Tissues were embedded in paraffin and ribbons of 2-3 sections cut at $5 \mu \mathrm{m}$ were stained with hematoxylin and eosin or with Gordon \& Sweet's reticulin stain. For convenience of sampling and measurement, morphometric quantification of airway changes was performed in sections of the longitudinally oriented trachea. Absence of alveolitis was confirmed in sections of the lungs of wild type mice.

\section{Morphometry}

To quantify the inflammatory response, hematoxylin and eosin stained sections were examined using a Leica Q500MC image analysis system (Leica, Cambridge, United Kingdom) calibrated with a reference measurement slide. For each animal, a section and an initial field of examination at one end of the section were selected at random. Using a $\times 40$ objective, nuclear profiles in the lamina propria (defined as the region bounded by the epithelial basement membrane and the luminal border of the tracheal cartilage plates) were counted in the field and the length of the epithelial basement membrane was measured. The microscope stage was then advanced a linear distance of two microscopic fields and the process was repeated, continuing in this manner until the full length of the tracheal section had been examined, which on average meant that five fields were analyzed per section. The data were used to calculate the mean number of cells per $100 \mu \mathrm{m}$ of epithelial basement membrane in the lamina propria for individual animals.

In parallel, the length of the epithelial basement membrane for the entire section was measured using a $\times 10$ objective. Then the full length of the epithelial surface was examined using a $\times 100$ oil immersion objective to enumerate intraepithelial eosinophils, which were readily identified on the basis of their strongly staining cytoplasmic granules. The data were expressed as number of cells per $\mathrm{mm}$ of epithelial basement membrane for individual animals.

The thickness of the epithelial layer was also measured in these sections, taking care to exclude fields in which the plane of section was tangential. Two standardized sampling points were used for measurement in each microscopic field, and 6 measurements were made per section. The mean thickness for each animal was calculated.

Reticulin stained sections were used for assessment of subepithelial collagenization. The image analysis system was used to directly measure the thickness of the reticulin-stained zone underneath the tracheal epithelium, using a $\times 40$ objective. Three standardized sampling points were used for measurement in each microscopic field, with an average of 18 measurements per section. The mean thickness for each animal was calculated.

\section{Airway Reactivity}

Responsiveness to methacholine was assessed in conscious, unrestrained mice by barometric plethysmography, using apparatus and software supplied by Buxco (Troy, New York). This system yields a dimensionless parameter known as enhanced Pause (Penh), reflecting changes in waveform of the pressure signal from the plethysmography chamber combined with a timing comparison of early and late expiration, which can be used to empirically monitor airway function. Measurement was performed essentially as previously described (Hamelmann et al, 1997a). Mice were placed in the chamber and baseline readings were 
taken and averaged for 3 minutes. Aerosolized methacholine (concentrations in solution ranging from 3.125 to $50 \mathrm{mg} / \mathrm{ml}$ ) was then delivered through an inlet into the chamber for 3 minutes and readings were averaged over a period of 3 minutes after each dose was administered.

\section{Statistical Analysis}

Results of morphometry and assessment of airway reactivity are presented as arithmetic mean \pm standard error for each experimental group. An initial one-way analysis of variance followed by NewmanKeuls multiple comparison test was used to examine differences between groups. The software package GraphPad Prism (GraphPad Software, San Diego, California) was used for all data analysis and preparation of graphs.

\section{References}

Amishima M, Munakata M, Nasuhara Y, Sato A, Takahashi T, Homma Y, and Kawakami Y (1998). Expression of epidermal growth factor and epidermal growth factor receptor immunoreactivity in the asthmatic human airway. Am J Respir Crit Care Med 157:1907-1912.

Bento AM and Hershenson MB (1998). Airway remodeling: potential contributions of subepithelial fibrosis and airway smooth muscle hypertrophy/hyperplasia to airway narrowing in asthma. Allergy Asthma Proc 19:353-358.

Bousquet J, Chanez P, Lacoste JY, Barneon G, Ghavanian N, Enander I, Venge P, Ahlstedt S, Simony-Lafontaine J, Godard $\mathrm{P}$, and Michel FB (1990). Eosinophilic inflammation in asthma. New Engl J Med 323:1033-1039.

Brunet LR, Finkelman FD, Cheever AW, Kopf MA, and Pearce EJ (1997). IL-4 protects against TNF- $\alpha$-mediated cachexia and death during acute schistosomiasis. J Immunol 159:777785.

Brusselle G, Kips J, Joos J, Bluethmann H, and Pauwels R (1995). Allergen-induced airway inflammation and bronchial responsiveness in wild-type and interleukin-4-deficient mice. Am J Respir Cell Mol Biol 12:254-259.

Corrigan CJ and Kay AB (1996). Chronic inflammation in asthma. In: Szefler SJ and Leung DYM, editors. Severe asthma-pathogenesis and clinical management. New York: Marcel Dekker, 103-127.

Corry DB, Folkesson HG, Warnock ML, Erle DJ, Matthay MA, Wiener-Kronish JP, and Locksley RM (1996). Interleukin 4, but not interleukin 5 or eosinophils, is required in a murine model of acute airway hyperreactivity. J Exp Med 183:109117.

Coyle AJ, Uchida D, Ackerman SJ, Mitzner W, and Irvin CG (1994). Role of cationic proteins in the airway. Hyperresponsiveness due to airway inflammation. Am J Respir Crit Care Med 150:S63-S71.

De Sanctis GT, Itoh A, Green FH, Qin S, Kimura T, Grobholz JK, Martin TR, Maki T, and Drazen JM (1997). T-lymphocytes regulate genetically determined airway hyperresponsiveness in mice. Nature Med 3:460-462.

Donnelly RP, Fenton MJ, Finbloom DS, and Gerrard TL (1990). Differential regulation of IL-1 production in human monocytes by IFN- $\gamma$ and IL-4. J Immunol 145:569-575.
Foster PS, Hogan SP, Ramsay AJ, Matthei KI, and Young IG (1996). Interleukin 5 deficiency abolishes eosinophilia, airways hyperreactivity, and lung damage in a mouse asthma model. J Exp Med 183:195-201.

Grunig G, Warnock M, Wakil AE, Venkayya R, Brombacher F, Rennick DM, Sheppard D, Mohrs M, Donaldson DD, Locksley RM, and Corry DM (1998). Requirement for IL-13 independently of IL-4 in experimental asthma. Science 282:22612263.

Hamelmann E, Schwarze J, Takeda K, Oshiba A, Larsen GL, Irvin CG, and Gelfand EW (1997a). Noninvasive measurement of airway responsiveness in allergic mice using barometric plethysmography. Am J Respir Crit Care Med 156:766-775.

Hamelmann E, Vella AT, Oshiba A, Kappler JW, Marrack P, and Gelfand EW (1997b). Allergic airway sensitization induces $T$ cell activation but not airway hyperresponsiveness in B cell-deficient mice. Proc Natl Acad Sci USA 94:1350-1355.

Hart PH, Vitti GF, Burgess DR, Whitty GA, Piccoli DS, and Hamilton JA (1989). Potential antiinflammatory effects of interleukin 4: Suppression of human monocyte tumor necrosis factor- $\alpha$, interleukin 1, and prostaglandin $E_{2}$. Proc Natl Acad Sci USA 86:3803-3807.

Hegele RG and Hogg C (1996). The pathology of asthma: an inflammatory disorder. In: Szefler SJ and Leung DYM, editors. Severe asthma-pathogenesis and clinical management. New York: Marcel Dekker, 61-76.

Hogan SP and Foster PS (1997). Cytokines as targets for the inhibition of eosinophilic inflammation. Pharmacol Ther 74 : 259-283.

Hogan SP, Koskinen A, and Foster PS (1997a). Interleukin-5 and eosinophils induce airway damage and bronchial hyperreactivity during allergic airway inflammation in BALB/c mice. Immunol Cell Biol 75:284-288.

Hogan SP, Koskinen A, Matthaei KI, Young IG, and Foster PS (1998a). Interleukin-5-producing CD4+ T cells play a pivotal role in aeroallergen-induced eosinophilia, bronchial hyperreactivity, and lung damage in mice. Am J Respir Crit Care Med 157:210-218.

Hogan SP, Matthaei KI, Young JM, Koskinen A, Young IG, and Foster PS (1998b). A novel T cell-regulated mechanism modulating allergen-induced airways hyperreactivity in BALB/C mice independently of IL-4 and IL-5. J Immunol 161:1501-1509.

Hogan SP, Mould A, Kikutani H, Ramsay AJ, and Foster PS (1997b). Aeroallergen-induced eosinophilic inflammation, lung damage, and airways hyperreactivity in mice can occur independently of IL-4 and allergen-specific immunoglobulins. J Clin Invest 99:1329-1339.

Humbert M, Corrigan CJ, Kimmitt P, Till SJ, Kay AB, and Durham SR (1997). Relationship between IL-4 and IL-5 mRNA expression and disease severity in atopic asthma. Am J Respir Crit Care Med 156:704-708.

Kopf M, Brombacher F, Hodgkin PD, Ramsay AJ, Milbourne EA, Dai WJ, Ovington KS, Behm CA, Kohler G, Young IG, and Matthaei KI (1996). IL-5-deficient mice have a developmental defect in CD5 + B-1 cells and lack eosinophilia but have normal antibody and cytotoxic $\mathrm{T}$ cell responses. Immunity 4:15-24. 
Kung TT, Stelts DM, Zurcher JA, Adams GK, Egan RW, Kreutner W, Watnick AS, Jones H, and Chapman RW (1995). Involvement of IL-5 in a murine model of allergic pulmonary inflammation: prophylactic and therapeutic effect of an antiIL-5 antibody. Am J Respir Cell Mol Biol 13:360-365.

Lambert AL, Winsett DW, Costa DL, Selgrade MK, and Gilmour MI (1998). Transfer of allergic airway responses with serum and lymphocytes from rats sensitized to dust mite. Am J Respir Crit Care Med 157:1991-1999.

McFadden ER and Gilbert IA (1992). Asthma. New Engl J Med 327:1928-1937.

Nakajima H, Iwamoto I, Tomoe S, Matsumura R, Tomioka H, Takatsu K, and Yoshida S (1992). CD4+ T-lymphocytes and interleukin-5 mediate antigen-induced eosinophil infiltration into the mouse trachea. Am Rev Respir Dis 146:374-377.

Noben-Trauth NP, Kropf P, and Muller I (1996). Susceptibility to Leishmania major infection in interleukin-4-deficient mice. Science 271:987-990.

Robertson CF, Dalton MF, Peat JK, Haby MM, Bauman A, Kennedy JD, and Landau LI (1998). Asthma and other atopic diseases in Australian children: Australian arm of the International Study of Asthma and Allergy in Childhood. Med J Aust 168:434-438.

Shah A, Church MK, and Holgate ST (1995). Tumour necrosis factor alpha: A potential mediator of asthma. Clin Exp Allergy 25:1038-1044.

Tang C, Rolland JM, Ward C, Bish R, Thien F, and Walters EH (1996). Seasonal comparison of cytokine profiles in atopic asthmatics and atopic non-asthmatics. Am J Respir Crit Care Med 154:1615-1622.

Temelkovski J, Hogan SP, Shepherd DP, Foster PS, and Kumar RK (1998). An improved murine model of asthma: selective airway inflammation, epithelial lesions and increased methacholine responsiveness following chronic exposure to aerosolised allergen. Thorax 53:849-856.
Thomas PS, Yates DH, and Barnes PJ (1995). Tumor necrosis factor- $\alpha$ increases airway responsiveness and sputum neutrophilia in normal human subjects. Am J Respir Crit Care Med 152:76-80.

Vignola AM, Chanez P, Chiappara G, Merendino A, Pace E, Rizzo A, La Rocca AM, Bellia V, Bonsignore G, and Bousquet $\mathrm{J}$ (1997). Transforming growth factor- $\beta$ expression in mucosal biopsies in asthma and chronic bronchitis. Am J Respir Crit Care Med 156:591-599.

Wills-Karp M, Luyimbazi J, Xu X, Schofield B, Neben TY, Karp CL, and Donaldson DD (1998). Interleukin-13: Central mediator of allergic asthma. Science 282:2258-2261.

Wilson JW and Li X (1997). The measurement of reticular basement membrane and submucosal collagen in the asthmatic airway. Clin Exp Allergy 27:363-371.

Yu CK, Yang BC, Lee SC, Wang JY, Hsiue TR, and Lei HY (1997). Dermatophagoides farinae-induced pulmonary eosinophilic inflammation in mice. Int Arch Allergy Immunol 112: 73-82.

Yung S, Durham SR, Corrigan CJ, Hamid Q, and Kay AB (1995). Phenotype of cells expressing mRNA for TH2-type (interleukin 4 and interleukin 5) and TH1-type (interleukin 2 and interferon $\gamma$ ) cytokines in bronchoalveolar lavage and bronchial biopsies from atopic asthmatic and normal control subjects. Am J Respir Cell Mol Biol 12:477-487.

Zhang S, Smartt H, Holgate ST, and Roche WR (1999). Growth factors secreted by bronchial epithelial cells control myofibroblast proliferation: an in vitro co-culture model of airway remodeling in asthma. Lab Invest 79:395-405. 